Provided by the author(s) and University of Galway in accordance with publisher policies. Please cite the published version when available.

\begin{tabular}{|c|l|}
\hline Title & $\begin{array}{l}\text { Tide-surge interactions and their effects on total sea levels in } \\
\text { Irish coastal waters }\end{array}$ \\
\hline Author(s) & $\begin{array}{l}\text { Olbert, Agnieszka Indiana; Nash, Stephen; Cunnane, Conleth; } \\
\text { Hartnett, Michael }\end{array}$ \\
\hline $\begin{array}{c}\text { Publication } \\
\text { Date }\end{array}$ & 2013-06 \\
\hline $\begin{array}{c}\text { Publication } \\
\text { Information }\end{array}$ & $\begin{array}{l}\text { Olbert, A., Nash, S., Cunnane, C., \& Hartnett, M. Tide-surge } \\
\text { waters. Ocean Dynamics, 63(6), 599-614. }\end{array}$ \\
\hline $\begin{array}{c}\text { Publisher } \\
\text { wink }\end{array}$ & Springer \\
\hline $\begin{array}{c}\text { Link to } \\
\text { version }\end{array}$ & http://dx.doi.org/10.1007/s10236-013-0618-0 \\
\hline $\begin{array}{c}\text { Item record } \\
\text { Dol }\end{array}$ & http://hdl.handle.net/10379/4128 \\
\hline
\end{tabular}

Some rights reserved. For more information, please see the item record link above. 


\title{
Tide-surge interactions and their effects on total sea levels in Irish coastal waters
}

\author{
Agnieszka Indiana Olbert ${ }^{\mathrm{a}, *}$, Stephen Nash ${ }^{\mathrm{a}}$, Conleth Cunnane ${ }^{\mathrm{b}}$, Michael Hartnett ${ }^{\mathrm{a}}$ \\ ${ }^{a}$ Civil Engineering, Ryan Institute, National University of Ireland, Galway \\ ${ }^{\mathrm{b}}$ Engineering Hydrology, National University of Ireland, Galway \\ * Corresponding author:
}

\author{
A.I. Olbert \\ tel.: +35391493208 \\ fax: +35391494507 \\ e-mail address: indiana.olbert@nuigalway.ie \\ postal address: Ryan Institute, NUIG, University Rd, Galway, Ireland
}

\begin{abstract}
The research presented in this paper involves the application of the joint probability method to the estimation of extreme water levels resulting from astronomical tides and surge residuals, and the investigation of the effects of tide-surge interactions on extreme water levels.

The distribution of tide peaks was analysed from field records ( $<20$ years) and a 46-year dataset of monthly maximum tidal amplitudes. Large surges were extracted from both field records and a numerical model hindcast covering the 48 largest storm events in the Irish Sea over the period 1959-2006. Extreme storm surges and tides were independently modelled using the GEV statistical model, and derived probability distributions were used to compute extreme water levels.

An important, and novel, aspect of this research is an analysis of tide-surge interactions and their effects on total water level; where interactions exist, they lead to lower total water levels than in the case of independency. The degree of decrease varies with interaction strength, magnitude of surge peak at a particular phase of tide, and the distribution of peaks over a tidal cycle. Therefore, including interactions in
\end{abstract}


the computation of extreme levels may provide very useful information at the design stage of coastal protection systems.

Keywords: surge residual, extreme water levels, coastal flooding, statistical model, joint probability model, tide-surge interactions

\section{Introduction}

Coastal flooding is usually associated with extreme sea levels due to the combined action of tides and surges. Coastal flooding can cause significant loss of life and damage to property (McRobie, 2005); the financial cost of flooding may be also considerable (Wolf and Flather, 2005). A good knowledge of the probability of flooding is, therefore, necessary for correct assessment of flood and coastal defence, and subsequently for decision-making, where benefit and cost are important (Hawkes, 2008).

Extreme coastal sea levels are the product of a combination of (a) a moderate-to-high surge occurring at spring high tide or (b) an extreme surge occurring with moderate-to-high tide. The most severe event occurs when an extreme storm surge coincides with high spring tide. Although extreme tides and surges can be well predicted, independently, with the help of observational data and numerical and statistical models, methods for determination of extreme water levels due to the combined effect of both components tend not to be very accurate; there is currently no universally accepted method (Haigh et al. 2010a). There are a number of approaches used to establish extreme water levels. In the most straightforward approach, extreme water levels are directly extracted from sea level records. The method requires a very long timeseries (>100 years) in order to be accurate and, therefore, its application is limited. The process of determining extreme water levels becomes much more complicated in the case of relatively short timeseries records when the statistics of extremes must be applied. A simple approach involves just the linear combination of the extremes values of tides and surges. Although the method is computationally inexpensive, the results are conservative, as the extreme values of both processes are assumed to occur at the same time. The joint probability method (JPM) developed by Pugh and Vassie (1980) greatly improves 
the estimations of extreme water levels by calculating the likelihood of simultaneous occurrences of extreme tides and surges. The successful application of the method is restricted, however, to sites that have several years of hourly records (> 25 years) and where tidal ranges are much larger than extreme surge residuals. The JPM method has been widely applied to various sites around the world, including the UK (Owen et al., 1997; Coles, 2001; Meadowcroft et al., 2004), the USA (Garrity et al., 2006), the Netherlands (van Gelder et al., 2004) and Argentina (D’Onofrio et al., 1999). The deficiencies of the JPM method were overcome in a revised joint probability method (RJPM) proposed by Tawn (1992) where extreme water levels are estimated from a pre-specified probability. This method has low prediction errors and is, therefore, recommended as a standard approach for estimating extreme sea levels (Haigh et al., 2010a). The standard and revised JPM methods described, although simplistic, are widely-used in coastal engineering; however, their reliability depends, not only, on the accuracy of extreme value statistics of tides and surges and associated problems with probability curve fitting, but also on the level of tide-surge interactions. While the former has been well-researched (e.g. Coles 2001) and is now relatively well resolved, the latter has been under-studied, to date, and its effect on accurate determination of extreme water levels undervalued.

In many coastal areas significant tides and surges co-occur and interact to varying degrees. The interactions occur when a remotely generated surge propagates with a tide, and the amplitudes and phases of both waves modulate each other (Rossiter 1961). Although this phenomenon has been subject to an investigation for over five decades no full physical explanation of all mechanisms has been presented to date. There are two dominant physical mechanisms of tide-surge interactions. The first mechanism manifests itself as a phase shift of the tidal signal due to the surge and, therefore, concerns the relative timing of tide-surge occurrence. Proudman $(1955,1957)$ investigated the impact of shallow water and bottom friction on the timing of high water. In shallow water positive surge increases a phase speed as a combined result of greater depth that advances the time of high water and depth-dependent frictional terms in the equation of motion (Rossiter 1961). Quantification of the contribution of shallow water and bottom friction to tidesurge interactions was given by Wolf (1981) who implied that the shallow water effect becomes dominant over quadratic friction for tidal amplitudes in excess of $3 \mathrm{~m}$ and depths of 10m or less. Where currents are strong the primary process responsible for this type of interaction is the bottom friction, which increases as 
the square of the current speed (Pugh, 1987). Prandle and Wolf (1978) observed this type of interaction in the estuary of the River Thames, where dynamics of wave propagation facilitate the maximum surge to peak on a rising tide, so preventing surge maxima from coinciding with high tides. In addition, Horsburgh and Wilson (2007) demonstrated that surge peaks avoid high water and larger tidal range reduces the risk of surge peaks arriving near high water. More recently, Haigh et al. (2010b) showed similar findings for the English Channel, while Olbert and Hartnett (2010) identified regions of strong and weak interactions and clear regional relationships between phase-of-tide and surge in the Irish coastal waters.

The second mechanism of interactions concerns a modulation of surge amplitude due to tide. As surge heights are related to water depth, they are larger in shallow water than in deeper water (McInnes et al. 2011). Shallow water interactions between tides and surges are likely to be responsible for the surge amplitude modification as a result of more energy being lost from tides and surges travelling together, than would be lost if they were travelling separately (Amin, 1982). Horburgh and Wilson (2007) showed that modulation of surge production is due to changes of depth during the tidal cycle. Prandle and Wolf (1978) found that surges occurring at high water are dampened while surges peaking on the rising tide tend to be amplified. Horburgh and Wilson (2007) added that surges are significantly greater at low water than at high water. This interpretation was used by Howard et al. (2010) to justify greater surge residuals close to low water in the Thames estuary. Surge amplification due to interactions is also sensitive to the shape and time profile of the surge such that amplification increases with decreasing surge duration (Prandle and Wolf 1978).

As described above, shallow water physics permits or prevents large surges from occurring at a particular phase of a tide; this also modulates the amplitude and timing of surge and tidal waves. The joint probability method does not account for tide-surge interactions. Excluding these interactions in the estimation of extreme water levels could, therefore, lead to considerable overestimation/underestimation of extreme sea levels. From these concerns, the two main objectives of this research emerge:

1. determination of the levels of tide-surge interactions in coastal waters

2. quantification of their effect on extreme water levels.

Irish waters, being frequently subjected to coastal flooding (Halcrow, 2008), were chosen to study tidesurge interactions and extreme sea levels. Two locations on the Irish coast: Cork Harbour in the Celtic Sea 
and Larne at the north entrance to the Irish Sea, as well as one location at the British coast - Barrow in Furness in the eastern Irish Sea were selected for analysis (for brevity these locations are referred henceforth as Cork, Larne and Barrow). For validation and comparison purposes two additional locations namely Bangor and Heysham were also analyzed. All five sites are shown in Fig. 1b. Site selection was motivated by the characteristics of each location. Cork has moderate tides and relatively low surges, Larne and Bangor are regarded as a low tide - high surge sites, while Barrow and Heysham are categorized as having both exceptionally high tides and surges. All three types of sites also have very different characteristics of tide-surge interactions, in terms of both the strength of tide-surge dependency and the distribution of peak surges over a tidal cycle.

The analysis of tide-surge interactions and extreme sea levels described in this paper is a multi-step process. Major surge and high astronomical tides events for the five locations were isolated. The extreme value analysis was carried out independently for tides and surge residuals using the GEV statistical model. Derived probability distributions were further utilized to compute a joint probability of extreme water levels. Tide-surge co-occurrence and their interactions were investigated, and a joint probability method was modified to accommodate these interactions. Finally, return water levels, and associated periods, for both tide-surge independent and dependent approaches were compared.

\section{Tides and surges in Irish coastal waters}

Water circulation in the Irish Sea is dominated by tides. The M2 and S2 semidiurnal constituents have greatest impact on local hydrodynamics with the M2 component being typically twice the S2 component.

Fig. 2 shows spatial distributions of M2 and S2 amplitudes obtained from the global FES99 tidal model (Lyard et al., 2006). Relatively low tidal ranges in the open ocean can increase substantially in the proximity of the coast as a result of shelving of the sea bed, funnelling, reflection of the tidal wave by the coastline, and resonance. In Irish coastal waters, higher tidal amplitudes occur in semi-enclosed regions and, in particular, in estuaries and bays. The Irish Sea is characterised by a complex distribution of coamplitude and co-phase contours due to its semi-enclosed nature and the high variability in bathymetry. 
Over $92 \%$ of the energy of the tidal motion within the Irish Sea is considered to stem directly from Atlantic tidal motion, rather than gravitational influences on the Irish Sea per se. The tides enter the Irish Sea from the Atlantic Ocean through the St. George’s Channel (south entrance) and North Channel (north entrance) with the two streams meeting in the vicinity of the Isle of Man. The northerly input of tidal energy is substantially lower than that entering by the St. George's Channel. The tide forms a standing wave as it propagates northwards into the Irish Sea with an amphidromic point positioned off the south-eastern Irish coast. A second amphidromic point is located in the North Channel.

While it is relatively easy to predict tides, storm surges are much more difficult to forecast and analyse due to their high variability. Irish coastal waters, due to connectivity with the Atlantic Ocean, are frequently affected by depression systems passing over the north-east Atlantic. The frequency and severity of storm surges vary seasonally and inter-annually depending upon climate modes (mainly the North Atlantic Oscillation).

The mechanism of storm surge formation and its propagation through Irish coastal waters has been recently investigated. The propagation of surges around the Irish coast is complex due to the open ocean waters of the west coast, the semi-enclosed nature of the Irish Sea and the complex bathymetry and topography (Olbert and Hartnett 2010). Jones and Davies (2006) maintain that oceanic flows and topography are the two major factors driving flow and influencing surge excursion on the shelf, but the severity of storm surges on the shelf depends primarily on wind forcing (Jones and Davies 1998) and resonant responses (Trupin and Wahr 1990).

Olbert and Hartnett (2010) investigated surge propagation mechanics and established a relationship between pathways of representative low pressure systems and associated surge distributions. Surges generated by northern, north-western, western and central storms peak initially along the western and southern coasts of Ireland, and then generally travel through the St. George’s Channel into the Irish Sea where a lower peak results. This is followed by a larger peak generated by the surge propagating into the Irish Sea from the North Channel. Surge peaks generated by storms travelling from the south act differently; they induce northward surge propagation and generate highest surges along the southern and western coastline. Fig. 3 presents the distributions of maximum surges in Irish coastal waters simulated for 48 surge events occurring in the period 1959-2005. Surge peaks along the south coast are $0.8 \mathrm{~m}$ high, while 
surges along the Northern Ireland coastline reach $1.5 \mathrm{~m}$. Surges on the west coast of Ireland are also generally higher than surges on the east coast.

\section{Methodology}

The extreme water level analysis was conducted by using two long timeseries of tide gauge records (Bangor and Heysham) in conjunction with numerical model outputs (Cork, Larne and Barrow). With regards to field records, frequencies less than 1 per 15 minutes were discarded in order to avoid underestimation of extreme levels. Data errors such as unrealistic spikes and spurious records were also excluded. As a result, the time periods of field records at the frequency and quality required for accurate determination of extremes were limited; for Bangor and Heysham the timeseries lengths were 14 and 19 years, respectively. These datasets were obtained from the British Oceanographic Data Centre (BODC). Where water level data were not available, extreme surges were determined from validated hydrodynamic model hindcasts. The analysis of surge residuals at three locations namely Cork, Larne and Barrow was conducted on a dataset of 48 extreme events over the 46-year period (1959-2005). In the case of astronomical tides at these three sites, a 46-year dataset of spring tide maxima was used to study the distribution of peak tides.

In this section, the surge numerical model, and its setup, is described, as are a statistical approach to extreme value analysis and the joint probability method used in the determination of extreme water levels.

\subsection{Surge model}

Simulation of surge conditions in the North East Atlantic and in the proximity of Cork was performed using the Princeton Ocean Model (POM). A detailed description and validation of this model can be found in Olbert and Hartnett (2010), thus, only a brief outline is given here. Although POM is a full three- 
dimensional hydrodynamic model, for computational economy a depth-averaged version of the model was used.

The POM hydrodynamic model resolves equations using hydrostatic assumption and the Boussinesq approximation. It is forced at the lateral boundaries by a variable surface elevation accounting for tidal input and meteorological conditions at the surface. Temporally- and spatially-variable wind stresses were applied to the model in the form of pressure and wind forcing. Wind stress was parameterized as a quadratic function of the $10 \mathrm{~m}$ wind speed; a varying drag coefficient defines changes in the roughness of the ocean surface. The bottom stress term is calculated as a quadratic function of the depth mean flow.

\subsection{Numerical model set-up and simulation period}

The numerical model covers an area of the North East Atlantic allowing radiation of far-field conditions to the coast and simulation of the response of the Celtic Sea and Irish Sea to external surge. The numerical domain is delineated by the coordinates: $30-0^{\circ} \mathrm{W}$ and $40-60^{\circ} \mathrm{N}$. The computation was carried out on a highresolution horizontal grid $\left(1 / 12^{\circ}\right.$ longitude by $1 / 24^{\circ}$ latitude). The grid spacing stability constraints imposed a time-step, $\Delta \mathrm{t}$, of 10 seconds. The model bathymetry was constructed from an amalgamation of the General Bathymetric Charts of the Oceans (GEBCO) 2004 dataset and the Irish National Seabed Survey data (INNS).

At the open boundary, a radiation condition relates the normal component of currents to the sea surface elevation. The simulation of astronomical tides in the model domain was driven by vertical oscillations of water levels defined at 5 open sea boundaries (Fig. 1a). Tidal spectra consisting of 5 constituents (K1, O1, M2, N2 and S2) were extracted from the FES99 dataset (Lyard et al. 2006) and interpolated on the NE Atlantic model grid (Kidner et al. 1999).

Hydrodynamic modeling was carried out for the largest 48 surge events recorded in the Irish Sea between 1959 and 2005. Event selection was based on a historical dataset of water elevations from gauges in Dublin Bay and Fishguard. De-tided timeseries were reviewed and surge residuals exceeding $0.5 \mathrm{~m}$ were considered as major surge events. The isolated surges were then hindcast by the model, forced from two 
atmospheric datasets: regional reanalysis ERA-40 data (Uppala et al. 2005) for the period 1959-1991 and operational model level first-guess data (Simmons et al. 1989) from year 1991 onwards. These datasets were obtained from the European Centre for Medium-Range Weather Forecasts (ECMWF) and consisted of mean sea level pressure and $10 \mathrm{~m}$ wind fields at 3-hour temporal resolution. Since the duration of individual storms varies, the simulation periods were storm dependent. Additionally, in order to allow for model spin-up and complete development of surge conditions, a 4-day period prior and 2-day period subsequent to the event was added to the simulation. Consequently, the shortest storm event simulated was 12 days and the longest was 21 days.

The parameter of interest from the model simulations for each of the storm events was surge residual. The residuals were obtained by running two models for each storm event. In the first run the model was forced by tides and meteorology (tide-surge model), while in the second run the model was forced only by tides (tide model). Water elevations were computed for each run and surge residuals were determined by subtracting a tide-only solution from the tide-surge solution.

The advantage of the analysis of surge residuals over the recently popular skew surges (e.g. van den Brink et al. 2003, Sterl et al. 2009) is that the surge residuals correlate with tides (when interactions exist). In contrast, skew surges do not exhibit such correlations (Howard et al. 2010) and were, therefore, unsuitable for this study.

\subsection{Statistical approach to extreme value analysis}

A characterization of peak distributions, and underlying properties, can be determined by means of percentiles and return periods. High percentile analysis gives a straightforward description of extreme conditions. The major advantage of this method is that it gives a robust result and avoids the difficulties associated with procedures of fitting the statistical distribution; however, the disadvantage of the method is that it requires a long timeseries. In contrast, probabilistic models developed from the field of extreme value statistics draw inferences about the extremes using data from relatively extreme values alone. Such statistical models are sensitive to the choice of the distribution and the fitting procedures (Woth et al. 
2006), nevertheless, they are frequently utilized in analyses of extreme tides and/or surges (Lowe et al. 2001; Butler et al. 2007; Stephenson and Tawn 2004) and are used here.

The probability of the exceedence $(p(z))$ of a water level $(Z)$ is the probability that the level will be exceeded in any given time period. The return period $\left(R_{T}\right)$ is the average number of time periods between occurrence of events equal to, or greater than, the given level. The probability that the level (x) will exceed a given level (z) in any given time period is:

$$
p(z)=1-F(z)=\int_{z}^{\infty} f(x) d x
$$

Where $f(z)$ and $F(z)$ are the probability density function (PDF) and the cumulative distribution function (CDF), respectively. The $R_{T}$ of level $\mathrm{Z}$ can be expressed as:

$$
R_{T}=1 / p(z)=1 /(1-F(z))
$$

A number of probabilistic models were assessed graphically (not all presented here) to help determine the quality of the fit of statistical models used to an extreme value distribution of tides and surges. In particular, the goodness of fit to the upper tail of the data probability distribution was tested. The generalized extreme value (GEV) model (Coles, 2001) was found to approximate the distribution of extreme tides and surges well, and was subsequently used to estimate extreme water levels due to tides and surges, and their return periods.

The cumulative distribution function of the GEV is

$F(x)=\exp \left[-\left(1+\xi\left(\frac{x-\mu}{\sigma}\right)\right)^{-1 / \xi}\right]$

where $\mu$ is a location parameter, $\sigma$ a scale parameter, and $\xi$ a shape parameter. Depending on the value of $\xi$, three types are distinguished: Gumbel distribution ( $\xi=0)$, Freshet distribution $(\xi>0)$ and Weibull distribution $(\xi<0)$. 


\subsection{Joint probability method}

The temporal distributions of extremely high sea levels are stochastic in nature, resulting from the random occurrence of storm surges relative to the phase of astronomical tides. Sea level, $\eta$, is considered as a sum of two unrelated components: surge residual, $y$, (stochastic component) and astronomical tide, $\eta-y$, (deterministic component). In the joint probability method developed by Pugh and Vassie (1980) and revised by Tawn (1992) these components are approached separately and the sea level is estimated from the JPM of the two components.

Joint exceedence extremes and associated joint exceedence return periods refer to the average time between occasions when both variables simultaneously exceed some specific value. If the PDF of tides is

$f_{t}(\eta-y)$ and the PDF of storm surges can be represented by $f_{s}(y)$, the PDF of the total water levels

$f(\eta)$ as a combined probability of two phenomena can be expressed mathematically as

$f(\eta)=\int_{-\infty}^{\infty} f_{t}(\eta-y) f_{s}(y) d y$

The joint $\operatorname{CDF} F(\eta)$ for a given extreme sea level $z$ is

$F(z)=\int_{-\infty}^{z} f(\eta) d \eta$

The return period for a given extreme sea level can be obtained by applying equation 2 .

When tide-surge interactions exist, the joint probability function is adapted so the surge PDF is a function of tidal level. This is done by calculating separate surge PDFs for different parts of the tidal range. The method is described in detail in Pugh and Vassie (1980) and Tawn (1992).

\section{Results}

\subsection{Model validation}

The surge numerical model was extensively validated using records of surface elevations for several historic storm events. The assessment of model performance was carried out in both the semi-enclosed 
basin of the Irish Sea and the open Celtic Sea. Validation results from four sites namely Cork, Bangor, Fishguard and Holyhead are presented here (see Fig. 1b for map of locations); additional validation results can be found in Olbert and Hartnett (2010). Water level records for Cork were available through the Irish Office of Public Works, while data for Bangor, Fishguard and Holyhead were obtained from British Oceanographic Data Centre. The process of acquiring surge residual from water elevation records involved firstly performing a harmonic analysis of recorded elevations, then calculating astronomical tidal heights from tidal constituents obtained from the harmonic analysis and finally subtracting the calculated astronomical tidal heights from the recorded water elevations.

Fig. 4 shows a comparison between numerical model output and field data at Cork and Bangor during a one-week period in October 2002 that covers a period when three depression systems developed successively in the proximity of the Irish coast. During this storm event there is good correlation between numerical model and field records for both stations. Magnitudes and timing of surge peaks are well reproduced and the visual appraisal of correlation is supported by the correlation coefficients of 0.84 (Bangor) and 0.83 (Cork). Other statistical diagnostics are root-mean-square-errors of 0.10 and $0.11 \mathrm{~m}$ and standard deviations of 0.10 and $0.11 \mathrm{~m}$ for Cork and Bangor, respectively. Comparison of simulated and observed peaks of surge residuals for two locations Fishguard and Holyhead is presented in Fig. 5. Selection of these sites was qualified by their long span of tidal gauge records (Fishguard from 1963, Holyhead from 1966). There is a good correlation between model and observations with Pearson correlation coefficient of 0.75 and 0.83 for Fishguard and Holyhead, respectively. Root-meansquare-errors (standard deviations) for these two locations are 0.11(0.09) and 0.10(0.09) $\mathrm{m}$. The difference between model and data could be partially attributed to three-hourly atmospheric forcing in the model. However, a low frequency of records before year 1993 (1 per hour) as oppose to numerical model output of 1 per 15 minutes could also explain some portion of the difference.

\subsection{Extreme value analysis of surges}

The analysis of extreme surges was based on storm surge events extracted from field records (Bangor and Heysham) and numerical model outputs (Cork, Larne and Barrow). In the case of the field records, each 
storm event was defined as the largest surge within each two-week period of the year. This gives 26 events in total within one year of records (surges below a threshold value were later discarded). The highest recorded surge at Bangor within the 14-year period was $1.18 \mathrm{~m}$. At Heysham the highest surge during the 19-year period was $2.37 \mathrm{~m}$. The analysis of surge extremes, based on hydrodynamic model hindcasts, was conducted on a dataset of maximum surge values obtained from 48 storm events. From each of the simulated storm events only the maximum surge value was extracted; within the dataset of 48 maxima, the highest surge values at Cork, Larne and Barrow were 0.81, 1.41 and 1.84 m, respectively.

The GEV statistical distribution was fitted to the data. In order to reduce the uncertainty associated with the selection of a probability density function, lower bound values were ignored. A peak-over-threshold (POT) level for surge residuals at each site was selected .The POT values, shown in density plot (Fig. 6a), indicate positive skewness of the GEV distribution for all five locations. The quality of the statistical model fit was assessed from quantile and probability plots presented in Fig. 6 (b) and (c), respectively. The surge residuals obtained from the GEV model (Weibull distribution for all 5 sites) represent a very good fit to numerical model outputs and field records. In addition, two CDFs plotted against each other are similar and the solution falls on the 45 deg line. Return levels of surge heights are shown in Fig. 6 (d); their confidence levels, however, at all locations except Heysham are wide. The fitted distributions were ultimately used to determine surge heights at return periods of interest. Estimates of return levels for selected return periods are summarized in Table 1. A surge of $0.89,1.50,2.22,1.59$ and $2.59 \mathrm{~m}$ is expected to occur once per 200 years at Cork, Larne, Barrow, Bangor and Heysham, respectively.

\subsection{Extreme value analysis of tides}

Maxima spring tide amplitudes were used to investigate the distribution of peak tides at all locations. At Bangor and Heysham these maxima were extracted from the BODC records. In the case of Cork, Larne and Barrow, each dataset, consisting of 1104 readings (24 values per annum), was isolated from a 46-year timeseries generated from over 60 individual tidal components (NOAA 1982). The accuracy of data was tested against harmonic datasets and information on site specific tidal characteristics (lowest astronomical 
tide, highest astronomical tide, and mean high water spring tide, MHWS). Basic statistics of mean, minimum and maximum values along with MHWS tide are summarized in Table 2. Mean spring maxima at all five locations correspond very well to MHWS tide levels extracted from Hewitt and Lees-Spalding (1982).

Density plots, presented in Fig. 7 (a), indicate symmetrical probability distributions for Larne, Barrow and Bangor tides, and a negatively skewed distribution for Cork and Heysham tides with the left tail being much longer than the right. Data quantile plots (Fig. 7b) show a good fit of the GEV model (Weibull distribution) to tidal data. This is followed by a good agreement between the two CDFs. Computed return levels were compared with tidal levels of the Admiralty Tide Tables for Cork (Cobh station). Astronomical tides are not expected to be substantially greater than the 18.6-year Saros cycle in any given return period. Return levels (summarized in Table 1) exhibit 200- and 20-year difference of 2, $5,10,3$ and 3 cm for Cork, Larne, Barrow, Bangor and Heysham, respectively.

\subsection{Tide-surge interactions}

In this section, surge dependency on the phase of the tide is investigated. If surge peaks are uniformly distributed over a tidal cycle, both components are assumed to be independent. However, if surge tends to peak more frequently on one phase than on another, then interactions exist (Haigh et al. 2010b). For this analysis the tidal cycle was divided into eight equal bands, each band representing a particular phase of tide. The surge peaks were reviewed for timings, and classified and assigned into groups depending on the tide-phase division they fall in to. The tide bands, against which peak residuals were counted, were defined from a tide-only run of the model.

Fig. 8 (a-d) illustrates the spatial distributions of surge peaks throughout a tidal range within the Irish coastal waters. There are no marked relationships between surge peak and phase of tide along southern coastline of Ireland (Cork). Interesting relationships emerge as surge and tide propagate into the Irish Sea. At southern entrance to the basin, up to $40 \%$ of surges tend to peak at low water, while in the eastern Irish Sea (Barrow and Heysham) approximately 60\% of surges coincide with mid flood. Strongest dependencies 
occur in the western Irish Sea and in the proximity of the North Channel (Larne and Bangor) where around $80 \%$ of surges peak at high tide. A consistency in a temporal sequence of peak events is also observed. Surges entering the Irish Sea from the south tend to peak just around low water (Fig. 8a), while surges further to the north develop their peaks at subsequent phases of rising tide. In the western Irish Sea and the North Channel, surge maxima coincide very strongly with high water (Fig. 8c).

Further in-depth analysis of tide-surge interactions was carried out for the five selected locations. As demonstrated in the spatial analysis, Cork, Larne and Barrow have very different characteristics of tidesurge interactions, in terms of both strength of tide-surge dependency and timing of peak surges over a tidal cycle. Due to their proximity, Larne and Bangor are likely to have very similar surge distribution, and the same is expected for the pairing of Barrow-Heysham. Fig. 9 (a-e) shows the distribution of surge peaks over the tidal cycle; if the surge and tide are independent processes, then the number of surges per one tidal band would be approximately 6 for Cork, Larne and Barrow, 32 for Bangor and 25 for Heysham. From the five locations it can be clearly seen that the distribution is non-uniform in each case but the level of dependency varies. In Cork, surges coincide with a rising tide between mid flood and high water.

Approximately 54\% of peaks fall into mid flood - high water bands, and of these approximately $42 \%$ (23\% of all surges) peak in a short period of c. $1.5 \mathrm{hr}$ starting around 4 hours after low water. Very strong tide-surge dependency is observed in Larne, where $52 \%$ of all peak surges occur within a 1.5 -hr time interval centred on high water. Interestingly, surges tend not to peak around mid tide. Observations for Larne are in contrast to observations at Barrow where there is a clear trend of surges coinciding with rising tide preceding mid flood (27\%) and around mid flood (38\%). Distribution of surge peaks over a tidal cycle at Bangor is very similar to that at Larne despite substantial differences in the number of storm events analysed, period of analysis and data origin (model, records). Similarly, Barrow and Heysham exhibit relatively good agreement in surge distribution leading to the conclusion that the number of modelled storm events is sufficient to perform tide-surge interaction analysis.

The level of dependency is quantified using the $\chi^{2}$ statistical test. For the $95 \%$ significance level and n-1 degrees of freedom $\left(\chi_{7,0.95}^{2}=14.07\right)$ the calculated $\chi^{2}$ for Cork, Larne, Barrow, Bangor and Heysham are correspondingly 12.0, 78.0, 38.0,124.0 and 81.1. These results suggest a strong dependence between surge and phase of tide at all locations except Cork characterized by a low degree of interactions. A similar test 
for tide-surge interaction was carried out for tidal height rather than tidal phase (Dixon and Tawn 1994). Interestingly, no dependency was found between surge residual and tidal height.

The degree of surge modification by tide was assessed by analysing the distribution of surge maxima over a low water to high water tidal range divided into eight equal bands. Fig. 10 presenting distribution of surge peaks (Fig. 10a) confirms findings from Fig. 9. At Cork surges clearly tend to peak on rising tide while at Larne and nearby Bangor a significant number of surge peaks coincides with high water. Surge peaks at Barrow, and nearby Heysham, tend to occur around mid water. Comparisons of surge height against tidal stage clearly show that for Cork the largest surges coincide with mid water (in fact on the rising tide), where mean surge height is, on average, $0.05 \mathrm{~m}$ greater than at the other stages. This finding is consistent with observations of amplified surges occurring at rising tide elsewhere (e.g. Prandle and Wolf 1978). At Larne and Bangor, highest mean surge occurs at low to mid water (band 2), which agrees with findings of Horsburgh and Wilson (2007), whereas at Barrow and nearby Heysham largest mean surges dominate close to high water (band 7) and at high water (band 8), respectively.

With regards to surge variance shown in Fig. 10 (c), there is a relatively small surge variance with tidal phase at Cork and a pronounced surge variance around mid water at Barrow and Heysham. This finding may indicate that there is a relationship between tidal phase and surge height at Cork and no such relationships at Barrow and Heysham.

This preliminary test of tide-surge wave modulation corroborates the presence of interactions. Although, in the case of the analyses for Cork, Larne and Barrow, the dataset of 48 surge maxima may not be sufficient to fully confirm these findings, the conclusions for Bangor and Heysham, based on 256 and 204 surges, are considered to be valid. Overall, comparison of analysis outcomes for the model and field records suggests that the methodology applied for the selection of modelled storm events and their number was appropriate and that the model accuracy was satisfactory. 


\subsection{Extreme water levels}

Extreme water levels are due to a combination of storm surge and astronomical tide, at the time of maximum surge close to highest tide. Within Irish coastal waters and the Irish Sea the combination of such characteristics may frequently occur in the North Channel (Larne, Bangor) and between the North Channel and Dublin, as well as along the entire west coast of Ireland where tide-surge interactions indicate a strong likelihood of simultaneous coincidence of peak surge and high tide (Fig. 8c). Such a combination would be relatively rare along the south and south-east coasts of Ireland and along the Welsh coast, and very unlikely on the west coast of England (Barrow, Heysham). In these regions, the maximum water levels are a combination of spring high tide and moderate surge.

In this research extreme water levels are determined using RJPM, where storm surge and tide are independently statistically modelled and their PDFs later merged in joint probability analysis. The normalized PDFs of tides and surges are used to construct a matrix, where each diagonal represents an observed level and the sum of the probabilities along that diagonal represents the probability of that observed level. Probabilities of water levels are ultimately converted to return periods. Full explanation of the method is given in Tawn (1992).

According to the RJPM approach, the storm events that contribute to water levels above the 10-year level do not include, solely, those storms with storm surges above the 10 year level. A storm with surge smaller than the 10-year level could contribute to the surge if it were to occur in combination with a tide curve above the 10-year level.

Table 3 presents extreme water levels calculated using the RJPM method. Assuming independence between tide and surge, the 50-year (200-year) return periods are 5.08 (5.18), 5.02 (5.15) and $11.62 \mathrm{~m}$ (11.93) for Cork, Larne and Barrow, respectively. For Bangor and Heysham these numbers are 5.08 (5.24) and 12.84 (13.00). The RJPM estimates are also compared to outputs from the simple addition method. For the 46year return period the difference in predicted extreme water levels using both methods is significant and amounts to $0.23,0.28$ and $0.64 \mathrm{~m}$ for Cork, Larne and Barrow, respectively. Interestingly, for these locations the 46-year return levels from the addition method are significantly larger than the 200-year return levels from the RJPM. Similar conclusions were drawn for Heysham, where extreme water level 
calculated from the 19-year tide and surge maxima using simple addition method exceed 200-year return level derived from the RJPM. At Bangor the 14-year maximum water level obtained by addition is approximately equal to the 50-year return level.

As shown in the previous section, tide-surge interactions do occur and for the considerable length of the Irish coastline large surges tend to occur with non-high-band tidal levels. Where such dependency exists, the probability of an extreme water level due to extreme tide and extreme surge may be lower than in the case when both components are independent. Recent modelling work by McInnes et al. (2011) for southeast Australia revealed that assumption of independence may lead to substantial overestimation of extreme water levels. Therefore, the relevant level of dependence must be built into the extreme sea level analysis, so that it does not tend to overestimate the extreme sea level where dependence exists. To accommodate interactions, the RJPM needs to be modified. While in the case of independence, one surge PDF generated from all surge events is incorporated in joint probability model, in the dependence case separate surge PDFs must be calculated for different tidal phases. Each of these PDFs is combined with corresponding section of tidal PDF in the RJPM. A similar approach has recently been used by Haigh et al. (2010a). Fig. 11 (a-e) shows predicted extreme water level curves for both tide-surge independency and dependency. In the case of Cork, including dependency does not alter extreme water levels significantly. The difference of $0.04 \mathrm{~m}$ for a 200 -year return period confirms that when the interactions are weak, the dependent solution will be close to the independent solution. Larne exhibits a $0.08 \mathrm{~m}$ lower extreme level when the dependent case is compared with the independent case. This is not a marked difference considering the relatively strong tide-surge interactions identified by this research, but could be attributed to the fact that surges at this site tend to coincide with high water and mean surge peaks at high tidal bands are relatively high. Similar conclusions can be drawn for Bangor, where the difference between the independent and dependent cases is merely $0.06 \mathrm{~m}$ for a 200-year return period. The effect of dependency is pronounced at Barrow and Heysham, where surges peak at mid tide and are prevented from peaking at high tide. Considering the large tidal range and surge heights at these sites, dependency affects the extreme water level quite markedly. This observation is in line with the findings of Prandle and Wolf (1978) who postulate that tide-surge interaction increases in direct proportion to both surge height and tidal range. As a result of these factors, the level of interactions is high and this is reflected in water levels. At Barrow the 200-year return level for 
the independent and dependent cases are $11.93 \mathrm{~m}$ and $11.30 \mathrm{~m}$, respectively, giving a $0.63 \mathrm{~m}$ difference. For Heysham this difference is even greater and reaches $0.86 \mathrm{~m}$.

The final stage of the tide-surge dependency analysis involves a comparison between observed maximum water levels and RJPM values. Black dots in Fig. 11 represent maximum observed water levels (also tabulated in Table 3). In all five cases there are discrepancies between the observations and RJPM estimates, with observed water levels being smaller than estimates from the RJPM. Although, the modified RJPM accounting for tide-surge interactions improves the prediction (particularly evident in case of Barrow and Heysham), the method generally tends to overestimate return levels and this conclusion is in agreement with the findings of Haigh et al. (2010a). Nevertheless, some portion of the discrepancies could be attributed to the quality of observed water levels and input dataset. Firstly, the length of field records for the analysis at Bangor and Heysham (14 and 19 years) may be too short to keep error estimates low at large return periods as at least 20 years of records is required for the RJPM (Haigh et al., 2010a). Secondly, a timeslice approach, as in the case of Cork, Larne and Barrow, was used to identify events of extreme surges only and, therefore, events of extreme water levels may have been overlooked. Nevertheless, the examples of Barrow and Heysham demonstrate that ignoring tide-surge interactions could lead to significant overestimation of water levels. Knowledge of such dependency is important for coastal defense purposes and for the design of costal structures.

\section{Conclusions}

This research investigates tide-surge interactions in coastal waters and their effects on total water level; these effects have not previously been investigated. Extreme storm surges and tides were independently modelled using the GEV statistical model and estimates of the 50-year return level were obtained. Tidesurge interactions and their co-occurrences were also analyzed and dependencies between tides and surges determined. Probability distributions of tides and surges were utilized to compute joint probability of extreme water levels. Subsequently, the joint probability method was modified to accommodate tide-surge interactions. Finally, return water levels for both the tide-surge independence and dependence approaches 
were compared and the superiority of the modified RJPM method over the standard RJPM was demonstrated.

The main conclusions from this research are as follows:

- In the presence of tide-surge interactions, the magnitude and phase of tidal and surge waves are modulated. Damping and amplifying effects of surge magnitude are site-specific. At some locations surges of largest magnitudes occur at rising tide, while at other locations they are highest around high water. Tidal phase modulation due to surge results in the frequency of surges peaking at the particular phase of tide. In general, where interactions exist, surges tend to peak at a particular phase of tide irrespective of the timing of the storm passage. Peak surges at some locations coincide frequently with high water or mid water, while at other locations are clearly prevented from occurring at these stages of tide.

- The degree of extreme water level modulation due to the tide-surge interactions is site-specific and may vary greatly from one location to another. The scale of modulation depends on tidal and surge regimes. Dealing with complex-topography coastal waters (such as the semi-enclosed Irish Sea) characterized by spatially variable amplitudes of tides and surges, requires that the analysis of extreme water levels is carried out separately for each site under consideration.

- Although for long return periods (>200years) extreme tides are not substantially greater than the maximum tidal amplitudes of the 18.6-year Saros cycle, and extreme surges are much higher than those obtained from the observations, the extreme water levels at majority of locations are still dominated by tides. The maximum water levels at all five sites investigated are generated at high tides despite the fact that surge values at high tide are often less than that at rising tide or that surge peaks occurring at high tide may be smaller.

- The modified RJPM, which takes account of tide-surge interactions, is an improved method. Although, it tends to overestimate the extreme sea levels where interactions exist, the error is much smaller than in the case of the standard RJPM that does not take account of interactions. The level of decrease in predicted levels varies with interaction strength, magnitude of surge peak at a particular phase of tide, and distribution of peaks over a tidal cycle. The standard RJPM may be 
considered as a more conservative approach, while the simple addition method, which greatly overestimates extreme water levels, is not recommended for applications.

Appropriate evaluation of tide-surge interactions is essential for accurate estimation of extreme sea levels. The modified RJPM, which includes interactions, not only improves the hydrological assessment but can also benefit the economics of coastal flooding defence systems as the lower extreme water levels resulting from the inclusion of interactions would result in a direct cost saving.

\section{Acknowledgements}

The study had been carried out while under funding of the Higher Education Authority Ireland, PRTLI

Cycle 4. Tidal gauge data for model validation were obtained from the British Oceanographic Data Centre and Irish Office of Public Works, Ireland. The authors would like to acknowledge the SFI/HEA Irish Centre for High-End Computing (ICHEC) for the provision of computational facilities and support.

\section{References}

Amin M (1982) On analysis and prediction of tides on the west coast of Great Britain. Geophysical Journal of the Royal Astronomical Society 68: 57-78.

Butler A, Heffernan JE, Tawn JA, Flather RA, Horsburgh KJ (2007) Extreme value analysis of decadal variations in storm surge elevations. Journal of Marine Systems 67: 189-200.

Coles SG (2001) An introduction to statistical modelling of extreme values. Springer, London. Dixon MJ, Tawn JA (1994) Extreme sea levels at the UK A-class sites: site-by-site analysis. POL internal document No. 65. 
D’Onofrio EE, Fiore MM, Romero SI (1999) Return periods of extreme water levels estimated for some vulnerable areas of Buenos Aires. Continental Shelf Research 19: 1681-1693.

Garrity NJ, Battalio PE, Hawkes PJ, Roupe D (2006) Evaluation of event and response approaches to estimate the 100-year coastal flood for Pacific coast sheltered waters. $30^{\text {th }}$ Int. Conf. Coastal Engineering, San Diego, 1651-1663.

Haigh ID, Nicholls R, Wells N (2010a) A comparison of the main methods for estimating probabilities of extreme still water levels. Coastal Engineering 57: 838-849.

Haigh ID, Nicholls R, Wells N (2010b) Assessing changes in extreme sea levels: Application to the English Channel, 1900-2006). Continental Shelf Research 30: 1042-1055.

Halcrow (2008) Lee Catchment Flood Risk Assessment and Management Study. Hydrology Report, April. OPW, Ireland.

Hawkes PJ (2008) Joint probability analysis for estimation of extremes. Journal of Hydraulic Research 46 (Extra Issue 2): 246-256.

Hewitt RL, Lees-Spalding IJ (1982) The Maximillan and Silk Cut nautical almanac. The Macmillan Press Ltd.

Horsburgh KJ, Wilson C (2007) Tide-surge interaction and its role in the distribution of surge residuals in the North Sea. Journal of Geophysical Research 112: C08003, doi:10.1029/2006JC004033.

Howard T, Lowe L, Horsburgh K (2010) Interpreting Century-Scale Changes in Southern North Sea Storm Surge Climate Derived from Coupled Model Simulations. J Climate 23: 6234-6247. 
Jones JE, Davies AM (1998) Strom surge computations for the Irish Sea using a three-dimensional numerical model including wave-current interaction. Continental Shelf Research 18: 201-251.

Jones JE, Davies AM (2006) Application of a finite element model (TELEMAC) to computing the wind induced response of the Irish Sea. Continental Shelf Research 26: 1519-1541.

Kidner D, Dorey M, Smith D (1999) What's the point? Interpolation and extrapolation with a regular grid DEM. In Proceedings 4th International Conference on GeoComputation. Mary Washington College Fredericksburg, Virginia, USA.

Lowe JA, Gregory JM, Flather RA (2001) Changes in the occurrence of storm surges around the United Kingdom under a future climate scenario using a dynamic storm surge model driven by the Hadley Centre climate models. Climate Dynamics 18: 179-188.

Lyard F, Lefevre F, Letellier T, Francis O (2006) Modelling the global ocean tides: modern insights from FES2004. Ocean Dynamics 56: 394-415.

McInnes KL, Macadam I, Hubbert G, O’Grady J (2011) As assessment of current and future vulnerability to coastal inundation due to sea-level extremes in Victoria, southeat Australia. International Journal of Climatology DOI: 10.1002/joc.3405

McRobie A, Spencer T, Gerritsen H (2005) The big flood: North Sea storm surge. Philos Trans R Soc Lond A 363: $1263-1270$.

Meadowcroft IC, Hawkes PJ, Surendran S (2004) Joint probability best practice guide: practical approaches for assessing combined sources of risk for flood and coastal risk managers. Defra Flood and Coastal Management Conference, University of New York, 6a(2): 1-10. 
NOAA (1982) Computer Applications to Tides in the National Ocean Survey. Supplement to the Manual of Harmonic Analysis and Prediction of Tides (Special Publication No. 98). National Ocean Service, National Oceanic and Atmospheric Administration, U.S. Department of Commerce, January 1982.

Olbert AI, Hartnett M (2010) Storms and surges in Irish coastal waters. Ocean Modelling 34: 50-62.

Owen MW, Hawkes PJ, Tawn JA, Bortot P (1997) The joint probability of waves and water levels: a rigorous but practical new approach. MAFF Conf. River and Coastal Engineering, University of Keele, B(4): 1-10.

Prandle D, Wolf J (1978) The interaction of surge and tide in the North Sea and river Thames. Geophysical Journal of the Royal Astronomical Society 55: 203-216.

Proudman J (1955) The propagation of tide and surge in an estuary. Proc R Soc Lond A231: 8-24.

Proudman J (1957) Oscillations of tide and surge in an estuary of finite length. J Fluid Mech 2: 371-382. Pugh Dt (1987) Tides, surges and mean sea levels - A handbook for engineers and scientists. John Wiley and Sons Ltd.

Pugh DT, Vassie JM (1980) Applications of the joint probability method for extreme sea level computations. Proc Inst Civ Eng 9: 361-372.

Rossiter JR (1961) Interaction between tide and surge in the Thames. Geophysical Journal of the Royal Astronomical Society 6: 29-53.

Simmons AJ, Burridge DM, Jarraud M, Girard C, Wergen W (1989) The ECMWF medium-range prediction models development of the numerical formulations and the impact of increased resolution. Meteorol Atmos Phys 40: 28-60. 
Stephenson A, Tawn JA (2004) Bayesian inference for extremes. Extremes 7: 291-307.

Sterl A, van den Brink H, de Vries H, Haarsma R, van Meijgaard E (2009) An ensemble study of extreme storm surge related water levels in the North Sea in a changing climate. Ocean Sci 5: 369-378.

Tawn JA (1992) Estimating probabilities of extreme sea-levels. Applied Statistics 41: 77-93.

Trupin A, Wahr J (1990) Spectroscopic analysis of global tide gauge sea level data. Geophys J Intern 100: 441-453.

Uppala SM, Kallberg PM, Simmons AJ, Andrae U, Bechtold V, Fiorino M, Gibson J, Haseler J, Hernandez A, Kelly G, Li X, Onogi K, Saarinen S, Sokka N, Allan R, Andersson E, Arpe K, Balmaseda M, Beljaars A, Berg L, Bidlot J, Bormann N, Caires S, Dethof A, Dragosavac M, Fisher M, Fuentes M, Hagemann S, Holm E, Hoskins B, Isaksen L, Janssen P, McNally A, Mahfouf J, Jenne R, Morcrette J, Rayner N, Saunders R, Simon P, Sterl A, Trenberth K, Untch A, Vasiljevic D, Viterbo P, Woollen J (2005) The ERA40 reanalysis. Quart J Roy Meteorol Soc 131: 2961-3012.

van den Brink HW, Koennen GP, Opsteegh JD (2003) The reliability of extreme surge levels, estimated from observational records of order hundred years. Journal of Coastal Research 18: 376-388.

van Gelder PHAJM, Vrijling JK, van Haarden DH (2004) Joint probability distribution for wave height, wind setup and wind speed. $29^{\text {th }}$ Int. Coastal Engineering, Lisbon, 1032-1046.

Wolf J, Flather RA (2005) Modelling waves and surges during the 1953 storm. Phil Trans R Soc A 363: $1359-1375$. 
Woth K, Weisse R, von Storch H (2006) Climate change and North Sea storm surge extremes: an ensemble study of storm surge extremes expected in a change projected by four different regional climate models.

Ocean Dynamics 56: 3-15.

\section{List of Figures}

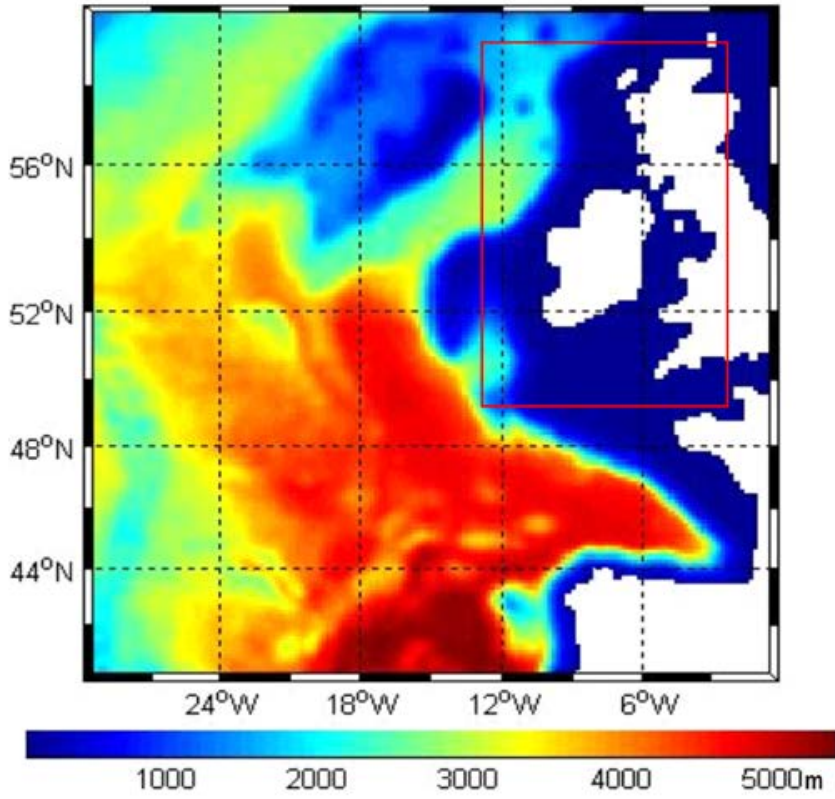

(a)

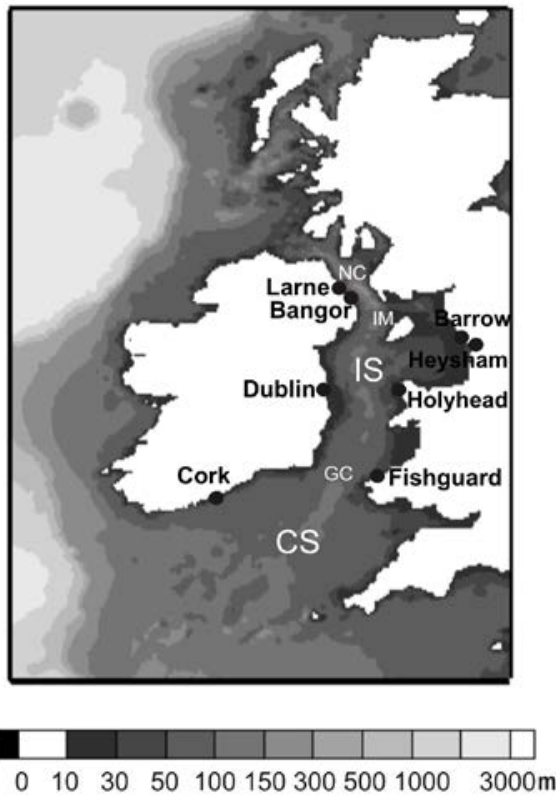

(b)

Fig.1 The bathymetry of North-East Atlantic model (a) and selected locations in Irish coastal waters (b). Abbreviations: IS - Irish Sea, CS - Celtic Sea, NC - North Channel, GC - St. George’s Channel, IM - Isle of Man 


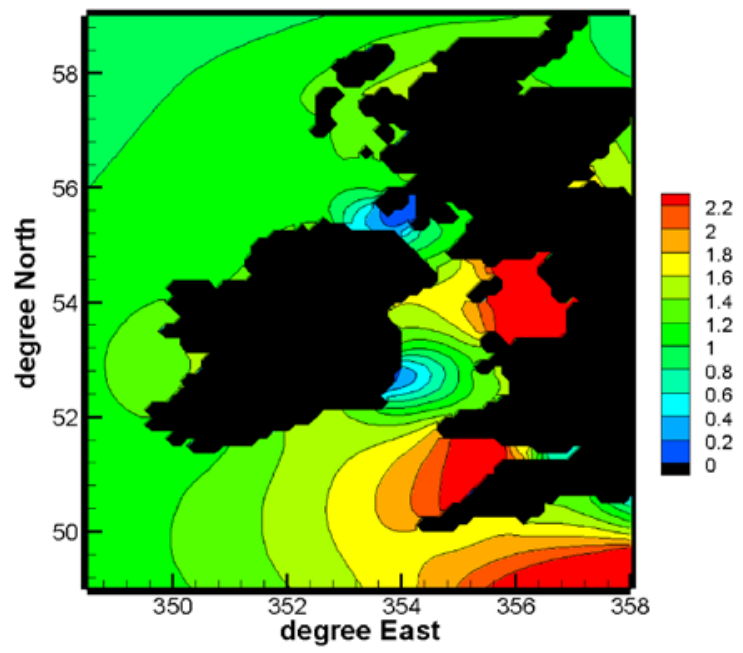

(a)

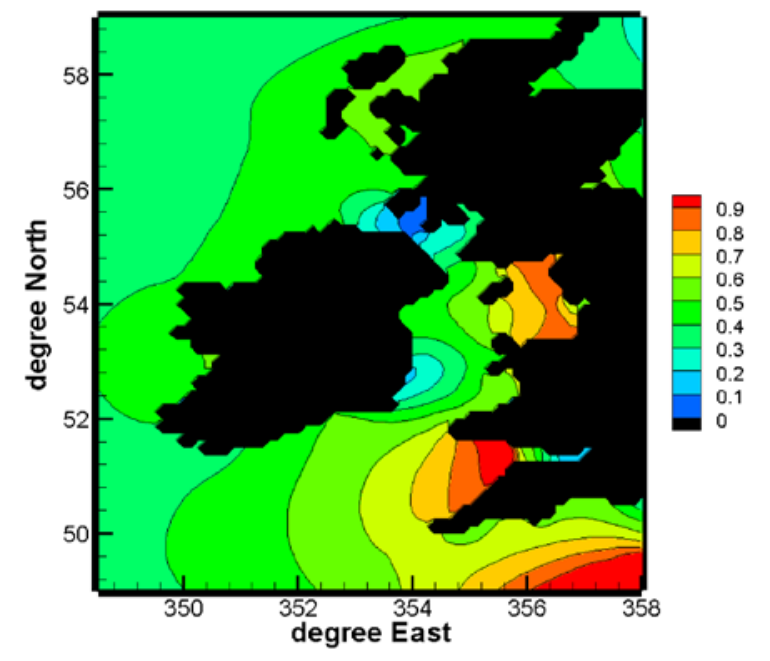

(b)

Fig. 2 Amplitude plots of (a) M2 and (b) S2 tidal constituents in Irish coastal waters

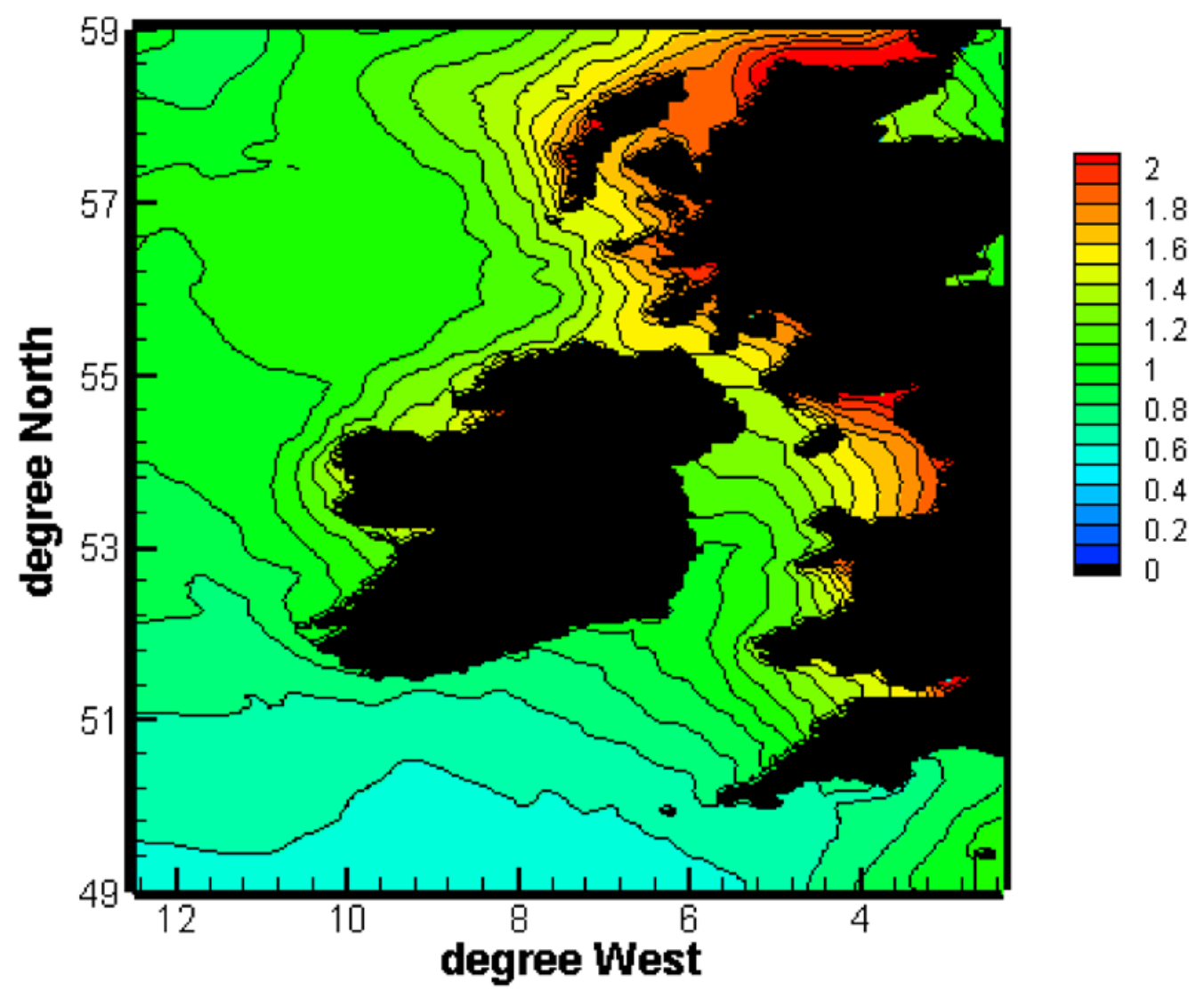

Fig. 3 Surge residuals expressed as $98^{\text {th }}$ percentile of simulated maximum surges for 48 surge events occurring in period 1959-2005 


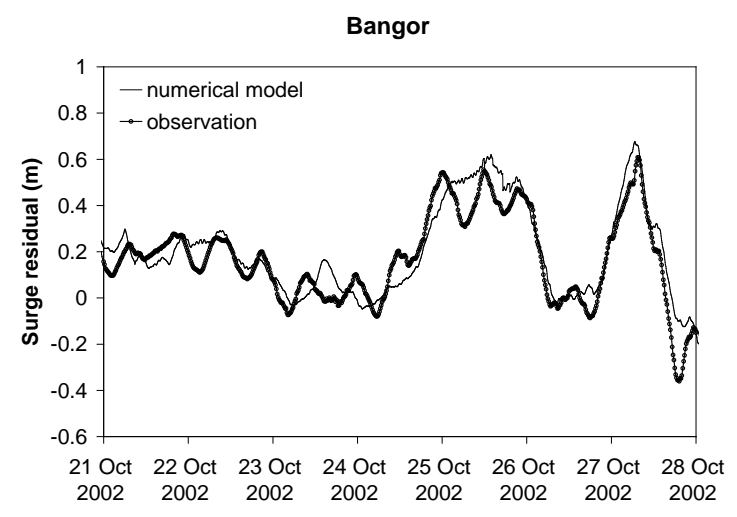

(a)

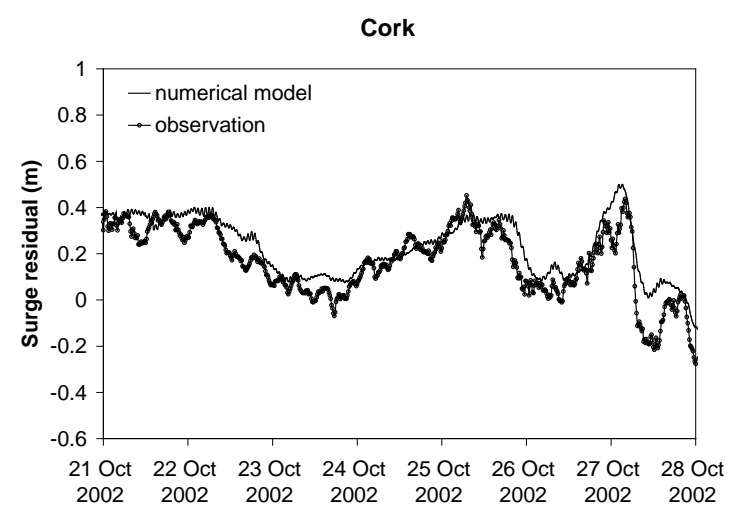

(b)

Fig. 4 Comparison of modelled and observed surge residuals at (a) Bangor and (b) Cork

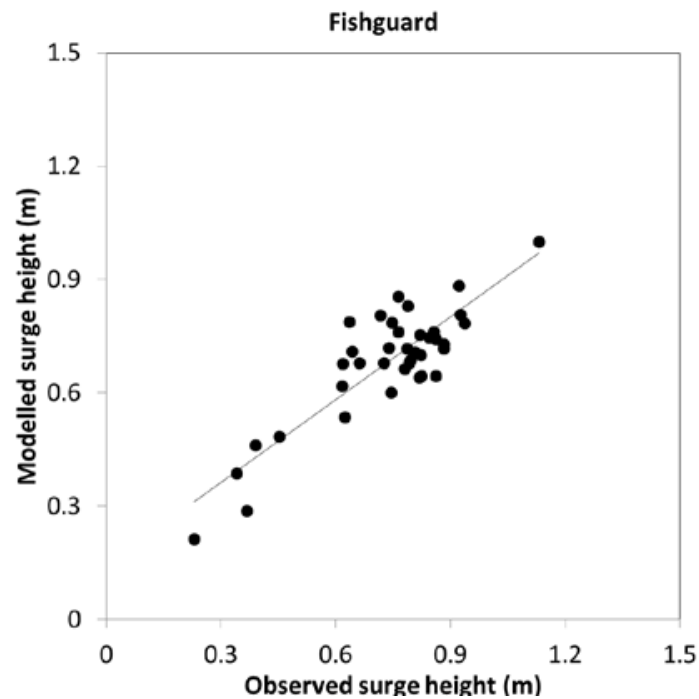

(a)

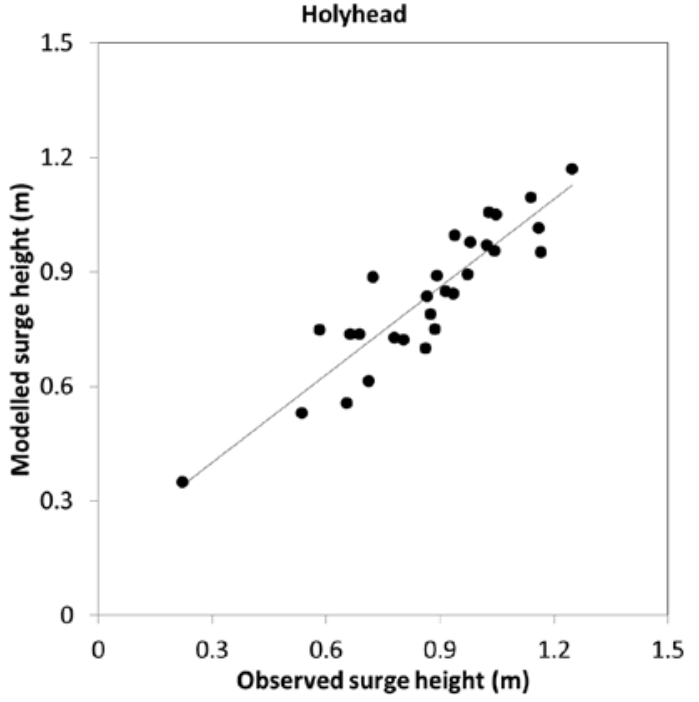

(b)

Fig. 5 Comparison of modelled and observed surge residuals peaks at (a) Fishguard and (b) Holyhead 

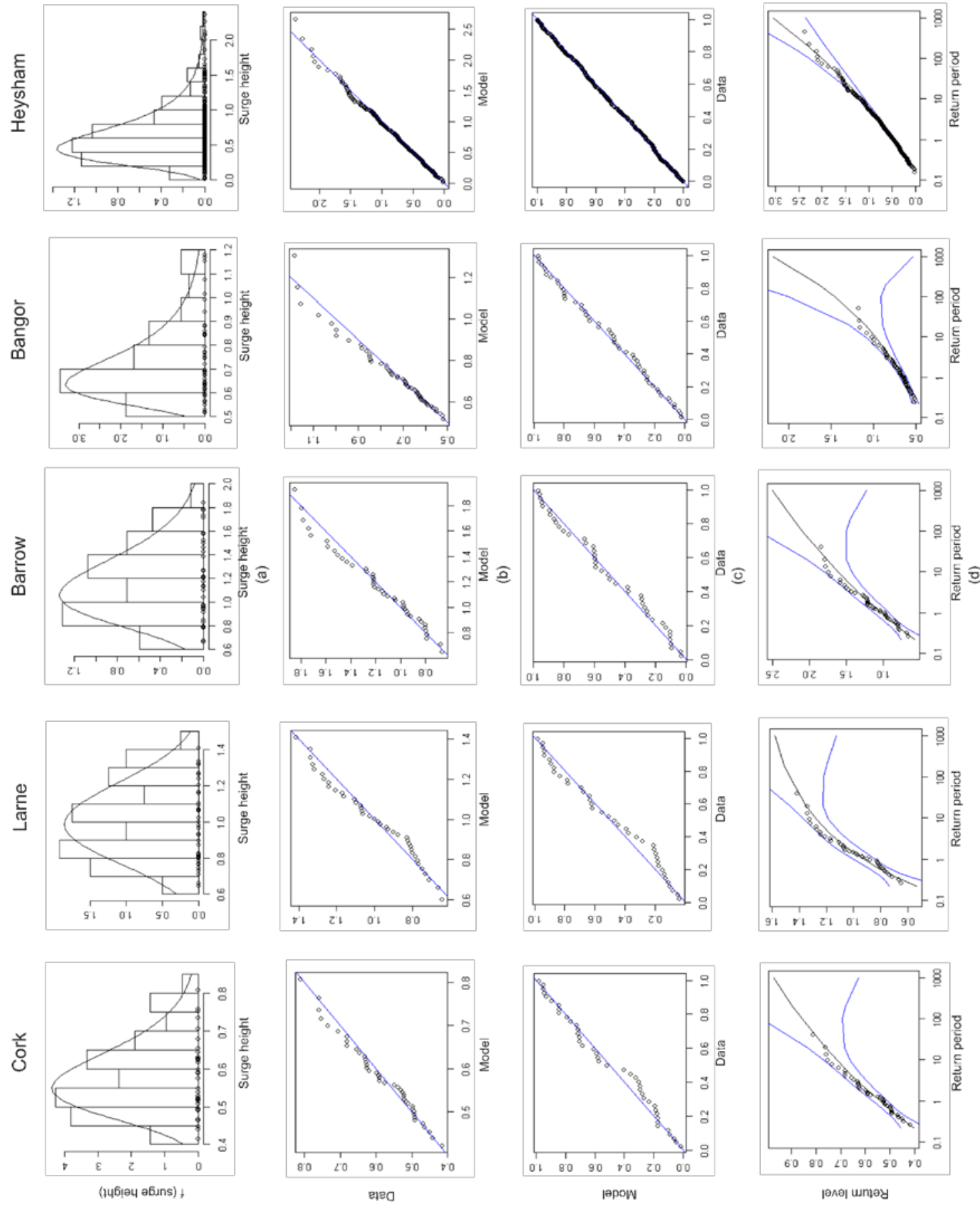

Fig. 6 Statistics of extreme surge residuals (a) density plot, (b) quantile plot, (c) probability plot and (d) return level plot. Comparison between surge data and GEV model 

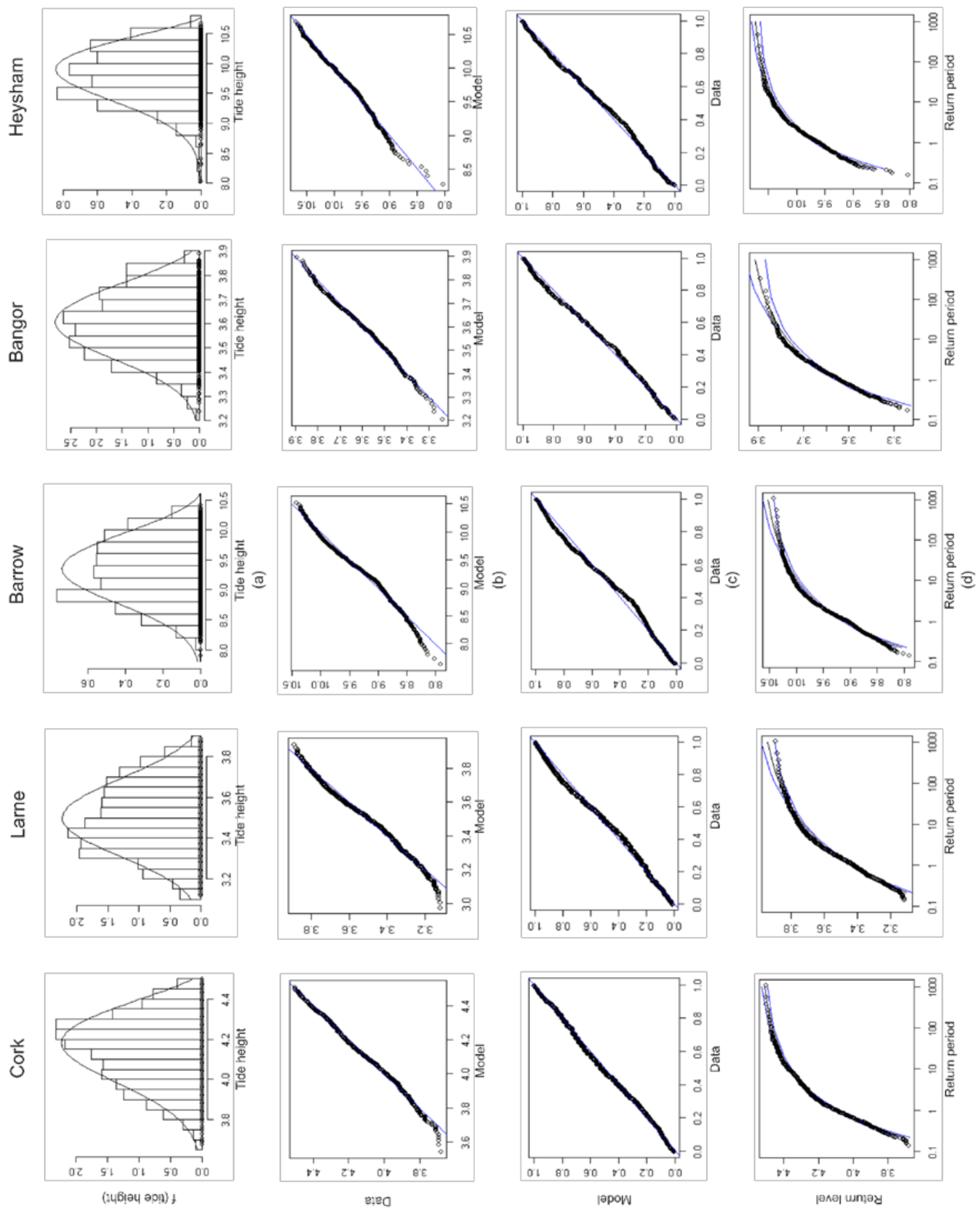

Fig. 7 Statistics of extreme tides (a) density plot, (b) quantile plot, (c) probability plot and (d) return level plot. Comparison between tidal data and GEV model 


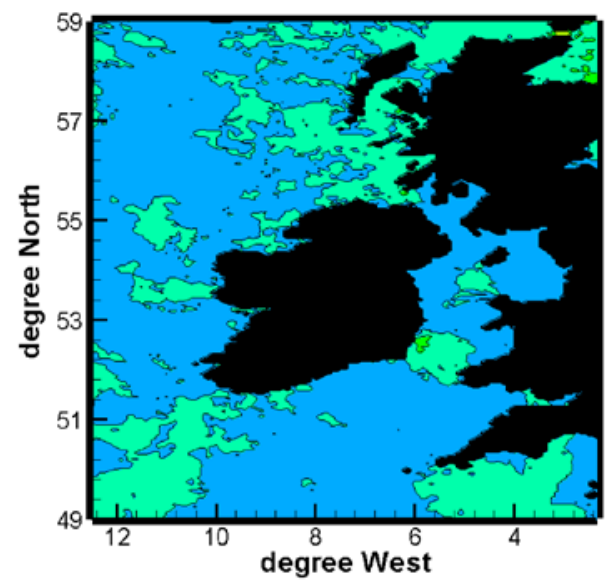

(a)

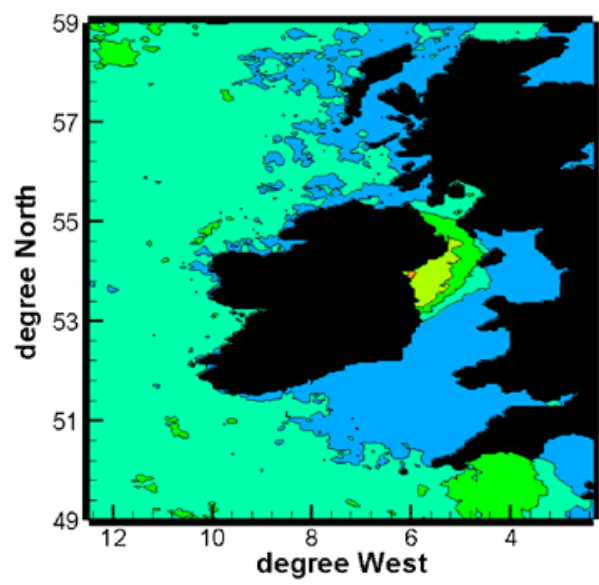

(c)

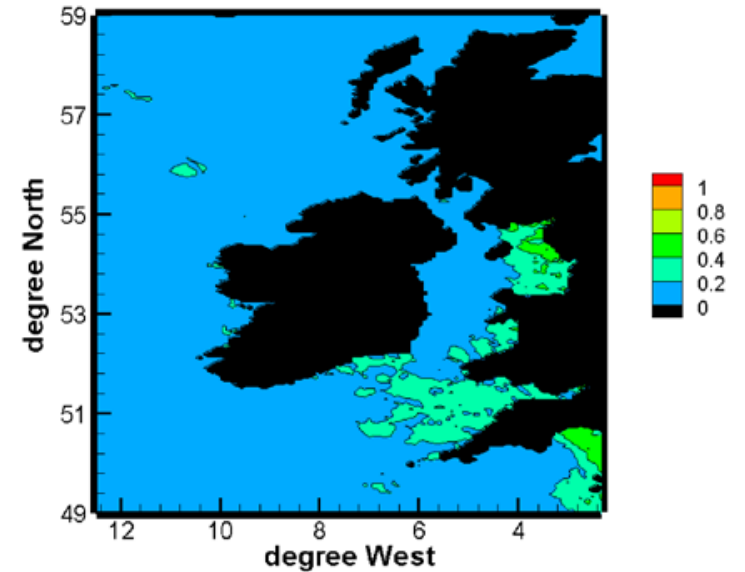

(b)

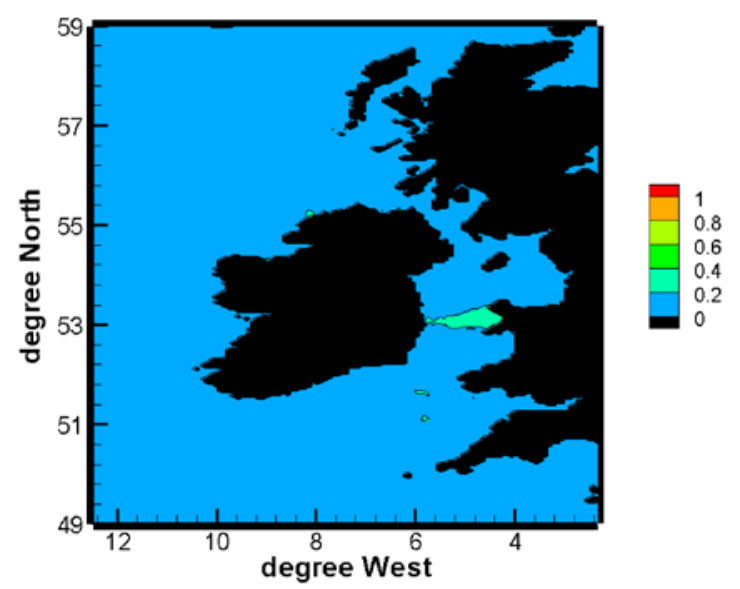

(d)

Fig. 8 Tide-surge interactions at (a) low water, (b) mid flood, (c) high water and (d) mid ebb. Values of 0 denotes no surge peaking at indicated phase of tide, 1 - all surges coincide with a particular phase of tide 


\section{Cork}

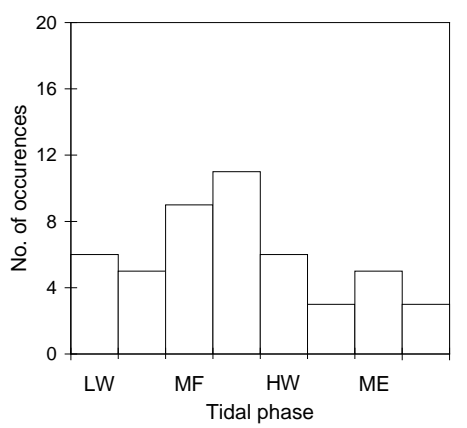

Bangor

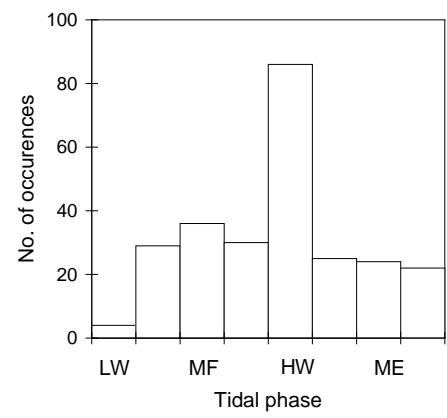

Larne

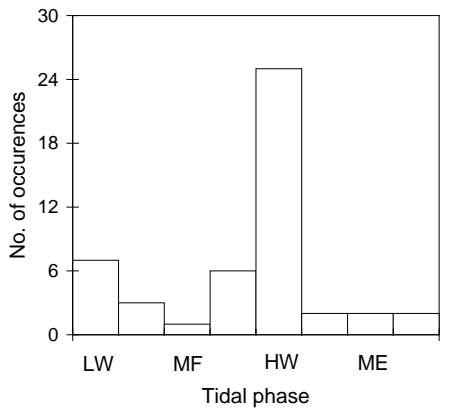

Heysham

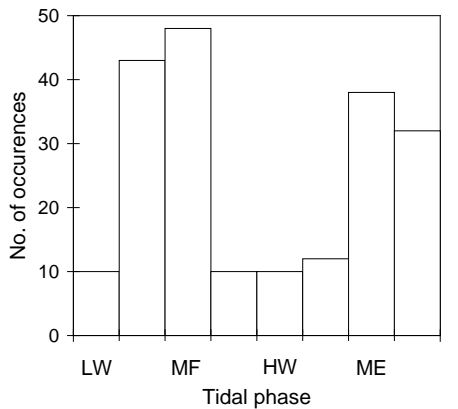

Fig. 9 Number of occurrences of surge peak at particular phase of tide. Abbreviations: LW - low water, MF - mid flood, HW - high water, ME - mid ebb

(a)

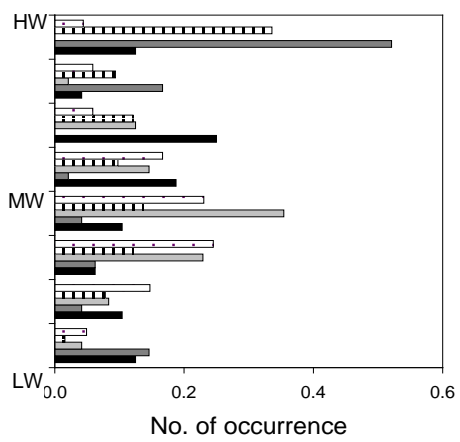

(b)

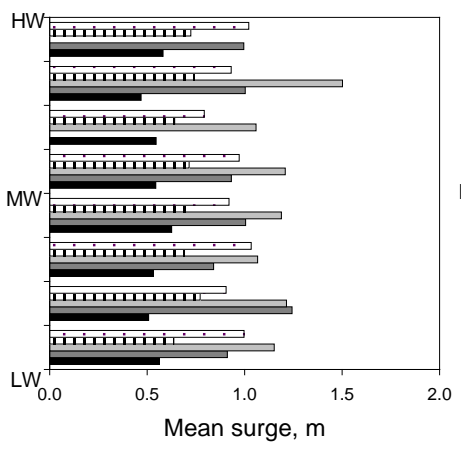

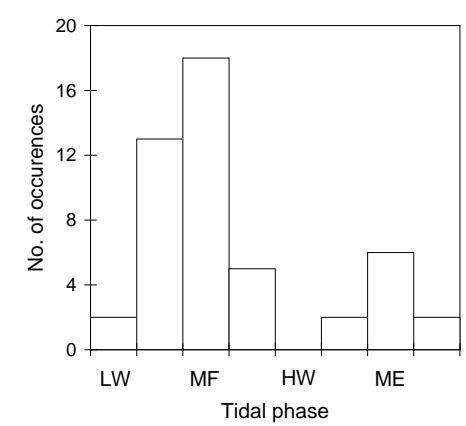

Barrow 
(a)

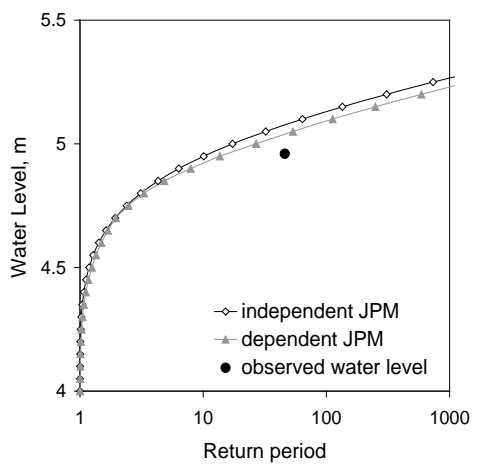

(d)

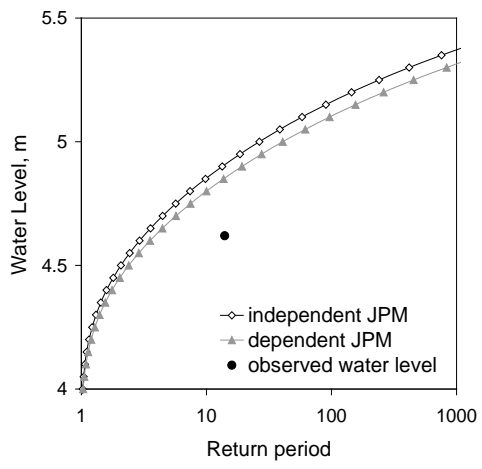

(b)

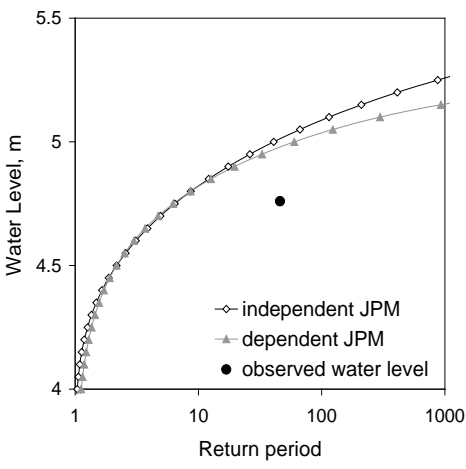

(e)

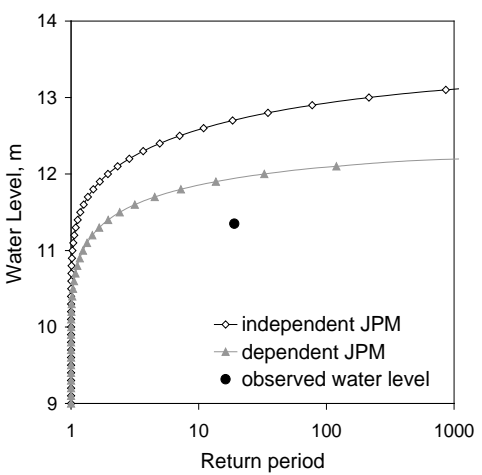

(c)

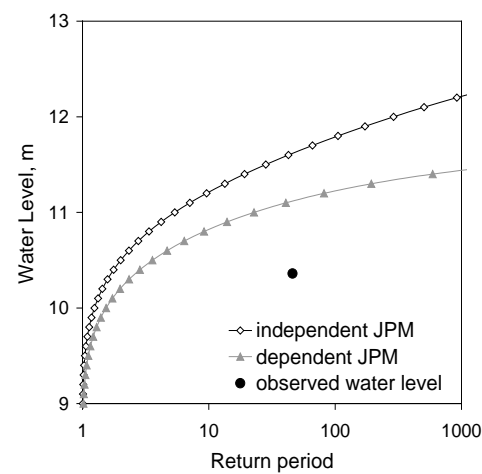

Fig. 11 Joint probability water elevations at (a) Cork, (b) Larne, (c) Barrow, (d) Bangor and (e) Heysham 
Table 1. Tide and surge return levels $(\mathrm{m})$ for selected return periods at five locations. Tides relative to Chart Datum (CD)

\begin{tabular}{|c|c|c|c|c|c|c|c|c|c|c|}
\hline & \multicolumn{2}{|c|}{ Cork } & \multicolumn{2}{c|}{ Larne } & \multicolumn{2}{c|}{ Barrow } & \multicolumn{2}{c|}{ Bangor } & \multicolumn{2}{c|}{ Heysham } \\
\hline $\begin{array}{c}\text { Return } \\
\text { period }\end{array}$ & Tide & Surge & Tide & Surge & Tide & Surge & Tide & Surge & Tide & Surge \\
\hline years & $\mathrm{m} \mathrm{CD}$ & $\mathrm{m}$ & $\mathrm{m}$ CD & $\mathrm{m}$ & $\mathrm{m}$ CD & $\mathrm{m}$ & $\mathrm{m}$ CD & $\mathrm{m}$ & $\mathrm{m}$ CD & $\mathrm{m}$ \\
\hline 2.00 & 4.45 & 0.56 & 3.83 & 0.94 & 10.27 & 1.14 & 3.84 & 0.92 & 10.59 & 1.65 \\
\hline 5.00 & 4.47 & 0.65 & 3.88 & 1.15 & 10.38 & 1.43 & 3.87 & 1.13 & 10.63 & 2.08 \\
\hline 10.00 & 4.49 & 0.70 & 3.90 & 1.25 & 10.44 & 1.61 & 3.89 & 1.25 & 10.65 & 2.26 \\
\hline 20.00 & 4.50 & 0.75 & 3.92 & 1.33 & 10.48 & 1.77 & 3.91 & 1.35 & 10.67 & 2.38 \\
\hline 50.00 & 4.51 & 0.81 & 3.94 & 1.41 & 10.53 & 1.96 & 3.92 & 1.46 & 10.69 & 2.49 \\
\hline 100.00 & 4.52 & 0.85 & 3.96 & 1.46 & 10.56 & 2.10 & 3.93 & 1.53 & 10.70 & 2.55 \\
\hline 200.00 & 4.52 & 0.89 & 3.97 & 1.50 & 10.58 & 2.22 & 3.94 & 1.59 & 10.70 & 2.59 \\
\hline 500.00 & 4.52 & 0.93 & 3.98 & 1.54 & 10.60 & 2.38 & 3.95 & 1.66 & 10.71 & 2.63 \\
\hline 1000.00 & 4.53 & 0.97 & 3.98 & 1.57 & 10.61 & 2.50 & 3.95 & 1.71 & 10.71 & 2.66 \\
\hline
\end{tabular}

Table 2. Statistics of high water levels on spring tide at five locations (relative to Chart Datum, mCD)

\begin{tabular}{|c|c|c|c|c|}
\hline \multirow{2}{*}{ Location } & \multicolumn{3}{|c|}{ High Water Spring level, mCD } \\
\cline { 2 - 5 } & Minimum & Maximum & Mean & $\begin{array}{c}\text { MHWS from tidal } \\
\text { charts }\end{array}$ \\
\hline Cork (Cobh) & 3.68 & 4.50 & 4.14 & 4.1 \\
\hline Larne & 3.12 & 3.89 & 3.50 & 3.5 \\
\hline Barrow & 7.93 & 10.42 & 9.32 & 9.3 \\
\hline Bangor & 3.24 & 3.89 & 3.59 & 3.5 \\
\hline Heysham & 8.04 & 10.68 & 9.78 & 9.7 \\
\hline
\end{tabular}

Table 3. Maxima of tides, surges and water levels for five locations and various return periods.

\begin{tabular}{|c|c|c|c|c|c|c|c|c|c|}
\hline \multirow[t]{3}{*}{ Location } & \multirow{3}{*}{$\begin{array}{l}\text { Dataset } \\
\text { length } \\
\text { (years) }\end{array}$} & \multirow{3}{*}{$\begin{array}{l}\text { Surge } \\
\max \\
(\mathrm{m})\end{array}$} & \multirow{3}{*}{$\begin{array}{c}\text { Tide } \\
\text { max } \\
\text { (mCD) }\end{array}$} & \multirow{3}{*}{$\begin{array}{c}\text { Water } \\
\text { level } \\
\text { max } \\
\text { (mCD) }\end{array}$} & \multicolumn{5}{|c|}{ Maximum water levels(mCD) } \\
\hline & & & & & \multirow{2}{*}{$\begin{array}{c}\text { Simple } \\
\text { addition } \\
\text { for } \\
\text { dataset } \\
\text { length }\end{array}$} & \multicolumn{2}{|c|}{ Independent RJPM } & \multicolumn{2}{|c|}{ Dependent RJPM } \\
\hline & & & & & & $\begin{array}{c}\text { 50-year } \\
\text { RP }\end{array}$ & $\begin{array}{c}\text { 200-year } \\
\text { RP }\end{array}$ & $\begin{array}{c}\text { 50-year } \\
\text { RP }\end{array}$ & $\begin{array}{c}\text { 200-year } \\
\text { RP }\end{array}$ \\
\hline Cork & 46 & 0.81 & 4.50 & 4.96 & 5.31 & 5.08 & 5.18 & 5.04 & 5.14 \\
\hline Larne & 46 & 1.41 & 3.89 & 4.76 & 5.30 & 5.02 & 5.15 & 4.98 & 5.07 \\
\hline Barrow & 46 & 1.84 & 10.42 & 10.36 & 12.26 & 11.62 & 11.93 & 11.14 & 11.30 \\
\hline Bangor & 14 & 1.18 & 3.89 & 4.62 & 5.07 & 5.08 & 5.24 & 5.02 & 5.18 \\
\hline Heysham & 19 & 2.37 & 10.68 & 11.35 & 13.05 & 12.84 & 13.00 & 12.04 & 12.14 \\
\hline
\end{tabular}

